\title{
Long-Term Hearing Outcome After Retrosigmoid Removal of Vestibular Schwannoma
}

\author{
Akira NAKAMIZO, ${ }^{1}$ Megumu MORI, ${ }^{1}$ Daisuke InOUE, ${ }^{1}$ Toshiyuki AMANO, ${ }^{1}$ \\ Masahiro MizOGUCHI, ${ }^{1}$ Koji YoshimOTO, ${ }^{1}$ and Tomio SASAKI ${ }^{1}$ \\ ${ }^{1}$ Department of Neurosurgery, Graduate School of Medical Sciences, \\ Kyushu University, Fukuoka, Fukuoka
}

\begin{abstract}
Although many investigators have reported the hearing function in the immediate postoperative period in patients with vestibular schwannoma (VS), little is known about the long-term outcomes of the postoperative hearing. The aim of this study was to analyze the long-term hearing outcomes at a mean followup of 5 years in patients with unilateral VS treated via the retrosigmoid approach. Twenty-four patients with immediate postoperative serviceable hearing who underwent repeated audiogram or phone interview were included in this study. During the mean follow-up period $(68.8 \pm 30.2$ months, range 14-123 months), serviceable hearing was preserved in 20 out of the 24 patients (83\%). Pure tone average (PTA) was reevaluated within 6 months in seven patients. In the two patients whose PTA deteriorated $\geq 5 \mathrm{~dB}$ in 6 months after surgery, their PTA worsened $\geq 15 \mathrm{~dB}$ compared to the immediate postoperative PTA. In the remaining five patients whose PTA deteriorated $<5 \mathrm{~dB}$ in 6 months after surgery, PTA was maintained within a 15-dB deterioration at the final follow-up ( $p=0.04$, Fisher's exact test). According to KaplanMeier survival plots, the 5-year or 7-year preservation rate of serviceable hearing was $\mathbf{8 6 . 2} \%$ or $71.8 \%$, respectively. Further study will be needed to clarify the mechanism underlying the long-term decline of serviceable hearing; however, the deterioration of PTA in the early postoperative period may help to predict the long-term outcomes of hearing.
\end{abstract}

Key words: long-term outcome, hearing, vestibular schwannoma, acoustic neuroma, retrosigmoid approach

\section{Introduction}

Although many studies offering descriptions of the rate of hearing preservation in the immediate postoperative period after vestibular schwannoma (VS) surgery have been published, ${ }^{6,9,15,24-26)}$ neurosurgeons tend to overlook the long-term outcomes of the preserved serviceable hearing. Several authors have assessed the changes of postoperative hearing function $^{2,3,7,11,13,14,16,21,27,31,32)}$; however, the follow-up periods were shorter than 5 years in most studies. A vast majority of studies have been reported from the Otolaryngology department. In those reports, the mean size of the tumors was small and the detailed information that might influence the hearing outcome was not discussed. . $7,13,16,21,23,27,31)$ The aim of this study was to analyze the long-term outcomes of serviceable hearing after retrosigmoid removal in the patients with unilateral VS at a mean follow-up of 5 years and to attempt to find the predictive factors

Received October 4, 2012; Accepted December 31, 2012 for the successful long-term hearing preservation.

\section{Patients and Methods}

Between 2002 and 2011, the senior author (Tomio Sasaki) performed surgery in 114 patients with unilateral VS via a retrosigmoid, lateral suboccipital approach at our institution. ${ }^{26)}$ Written informed consent was obtained from all patients. Patients with bilateral acoustic tumors (neurofibromatosis Type 2) were excluded from this study. In all patients, pure tone average (PTA) and speech discrimination score (SDS) were evaluated by audiologists, and 57 patients had retained useful hearing on the tumor side preoperatively (defined as PTA $\leq 50 \mathrm{~dB}$ and SDS $\geq 50 \%$; Gardner-Robertson [GR] Classifications I and II). ${ }^{8)}$ The waveform of preoperative auditory brainstem response (ABR) was divided into four groups: intact morphology, normal ABR waveform with delayed $\mathrm{V}$ wave latency (V delay), only I wave, and no response. There were no pure intracanalicular tumors in our cases, and the volume of the tumor 
in the cerebellopontine cistern was measured in all cases on preoperative magnetic resonance (MR) images. Tumor characteristics were divided into solid, cystic, or necrotic based on preoperative MR imaging and intraoperative findings. The extent of tumor removal was evaluated by postoperative MR images as described previously. ${ }^{18,26)}$ Intraoperative appearances of the eighth cranial nerve were divided into fanning and bundle. Postoperative serviceable hearing was defined by assessments of PTA and SDS (i.e., GR Classifications I and II). Twenty-eight out of 57 patients retained serviceable hearing postoperatively. An effort was made to acquire audiograms of patients without recent audiologic data. Letters and informed consents were mailed to the patients requesting a recent audiogram. Four of 28 patients were lost to follow-up, and 24 patients were included in this study. There was no difference in patients' characteristics between the included and excluded patients. Five patients did not agree to undergo audiogram; however, they accepted to give interviews by phone. For them, hearing was defined as serviceable in cases in which they could hear the voice and converse using the operated ear. Nineteen out of 28 patients with postoperative serviceable hearing underwent repeated audiogram longer than 1 year. Because SDS was not routinely conducted at all intervals, the serviceable hearing during the follow-up period was defined as PTA $\leq 50 \mathrm{~dB}$. Significant hearing loss was considered to be an increase in PTA of $15 \mathrm{~dB}$ compared to PTA at immediate postoperative period according to the criteria of Thornton and Raffin. ${ }^{30)}$

There were 8 men and 16 women with a mean age of $45.2 \pm 11.1$ years (range 22-62 years) at the operations (Table 1). Age was not an exclusion criterion; however, there was no patient older than 65 years in this analysis because we took a wait-and-see approach for the aged patients who harbored small VSs. There were 12 right-sided lesions and 12 left-sided lesions. The mean volume of the tumor was $4.5 \pm 8.1 \mathrm{~cm}^{3}$ ranging from 0.1 $\mathrm{cm}^{3}$ to $35.0 \mathrm{~cm}^{3}$. Total or near-total resection was achieved in 21 tumors and subtotal resection in 3 . In cases in which the internal auditory canal (IAC) was opened, posterior wall of the IAC was packed with fat, oxidized cellulose cotton, and fibrin glue. Care was taken to maintain sufficient space between the eighth cranial nerve and fat in order to make nothing adhere to the eighth cranial nerve. The mean follow-up period for audiometry or phone interview was $68.8 \pm 30.2$ months $( \pm \mathrm{SD}$, range 14-123 months). Among all the patients, recurrent tumors were not found by MR images during the follow-up period.
Commercially available software (JMP version 9; SAS Institute, Cary, North Carolina, USA) was used for statistical analysis. Multiple regression analysis was performed to study predictors for the long-term hearing outcomes. The significance was indicated by a value of $\mathrm{p}<0.05$. Wilcoxon rank test was utilized for nonparametric comparison, and the hearing preservation rates were established using the Kaplan-Meier product-limit method. Prism version 5.0 software (GraphPad Software, Inc., San Diego, California, USA) was used for Fisher's exact test.

\section{Results}

Individual sequential audiometry plotting of 19 patients is summarized in Fig. 1. In most patients, PTA of the operated ear deteriorated immediately after surgery, and then it was unchanged or slightly deteriorated (Fig. 1A). In contrast, PTA of the contralateral ear was maintained during the follow-up; PTA was less than $30 \mathrm{~dB}$ in 17 out of 19 patients and $33.8 \mathrm{~dB}$ or $60.0 \mathrm{~dB}$ in 2 whose immediate postoperative PTA was already $31.7 \mathrm{~dB}$ or $73.3 \mathrm{~dB}$, respectively (Fig. 1B). Interestingly, PTA of the contralateral ear deteriorated transiently immediately after surgery in 6 of 19 patients, and it improved in five cases during the follow-up. PTA of the operated ear remained unchanged or within $\mathrm{a} \leq 15-\mathrm{dB}$ deterioration (hearing preserved) in 13 patients during the follow-up period (Fig. 2A), whereas it deteriorated $>15 \mathrm{~dB}$ (significant hearing loss) in six (Fig. 2B). PTA was reevaluated within 6 months in seven patients. In the two patients whose PTA deteriorated $\geq 5 \mathrm{~dB}$ in 6 months after surgery, their PTA worsened $\geq 15 \mathrm{~dB}$ compared to the immediate postoperative PTA. In the remaining five patients whose PTA deteriorated $<5 \mathrm{~dB}$ in 6 months after surgery, PTA was maintained within a 15- $\mathrm{dB}$ deterioration at the final follow-up ( $\mathrm{p}=$ 0.04 , Fisher's exact test). Serviceable hearing was preserved in 20 of the 24 patients $(83 \%)$ during the follow-up period (Table 1). In one patient whose preoperative and immediate postoperative PTAs were $44.2 \mathrm{~dB}$ and $45.0 \mathrm{~dB}$, respectively, hearing declined to the nonserviceable level at 54 months after surgery despite her PTA deteriorated only 7.5 $\mathrm{dB}$ (Case 17 in Table 1).

According to Kaplan-Meier survival plots, the 5-year or 7-year preservation rate of serviceable hearing in 19 patients who underwent repeated PTA was $86.2 \%$ or $71.8 \%$, respectively (Fig. 3A). The 5 -year or 7 -year provability without significant hearing loss (defined as remained unchanged or within $\mathrm{a} \leq 15-\mathrm{dB}$ deterioration of PTA according to the criteria of Thornton and Raffin) was $82.6 \%$ 
串

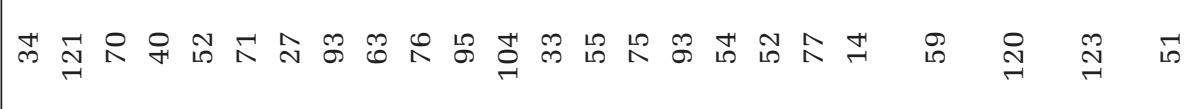

$\pi \frac{2}{\pi}$ ^ ร

$\ll 8 \ll$

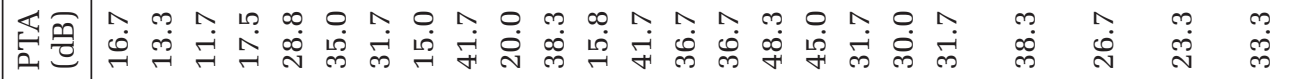

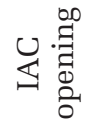

$\stackrel{\infty}{\infty}$

$\stackrel{\infty}{\infty}$

$\stackrel{\infty}{\infty} \underset{1}{\infty}$

$\stackrel{\infty}{\infty}$

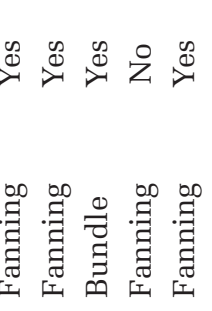

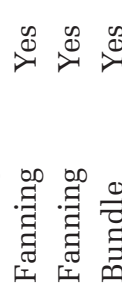

是是:

争

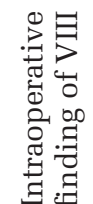

节

葛营

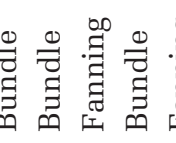

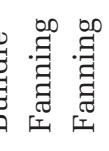

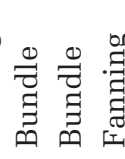

窝

$\stackrel{\infty}{\infty} \overbrace{\nu}^{\infty}$

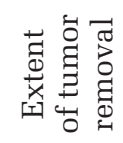

퓸

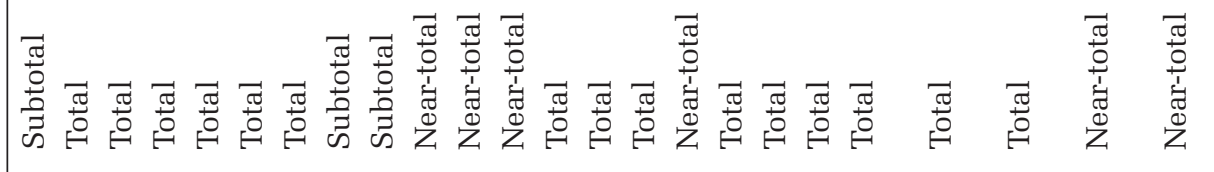

当

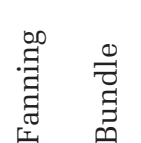

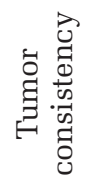

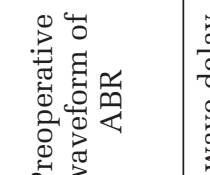

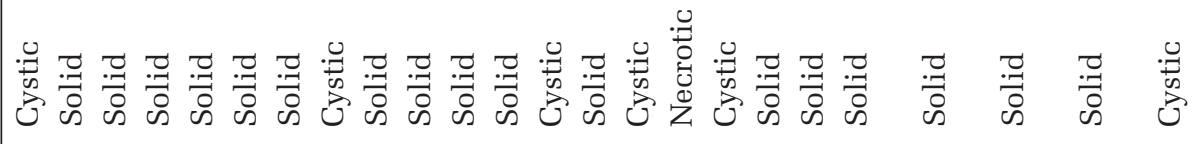

स 3

离
0
0
0
0
0
3
$>$
$>$

坖党

(a)

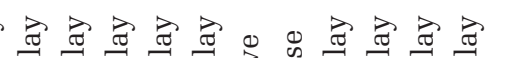

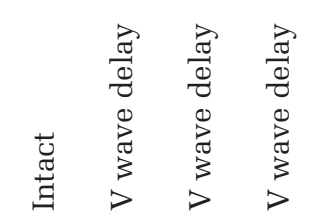

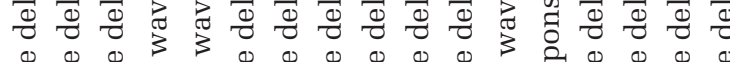

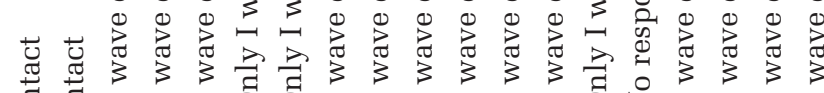

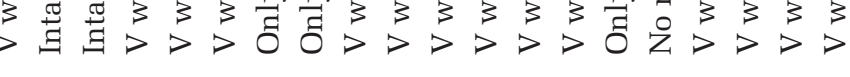

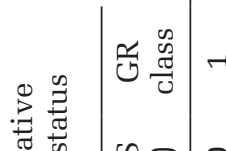

要, 分

$\underset{\sim}{\stackrel{ }{\circ}}$

$\stackrel{\circ}{\circ}$

幽

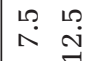

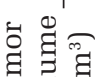

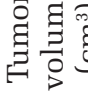

节薷

崖

包

เุด

งิ

今ิ

$\hat{\text { 今 }}$

일

m

욕 \& \& 
A

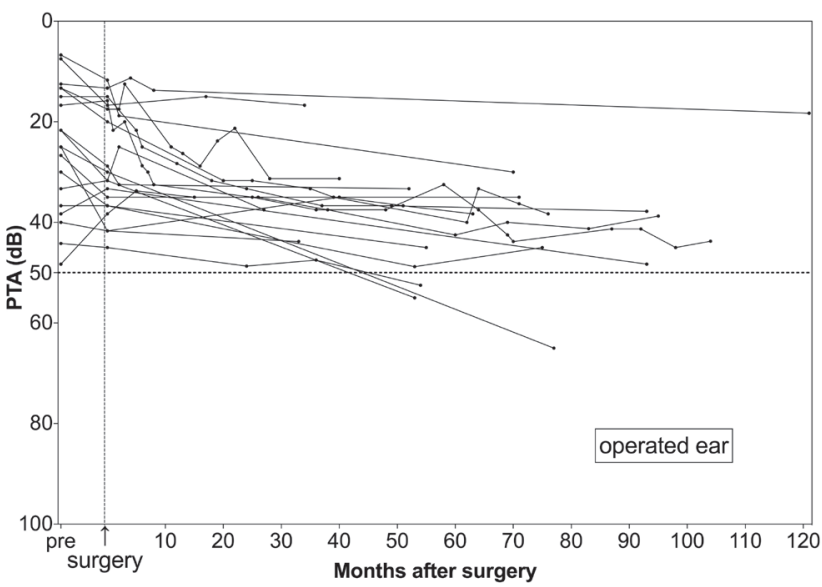

B

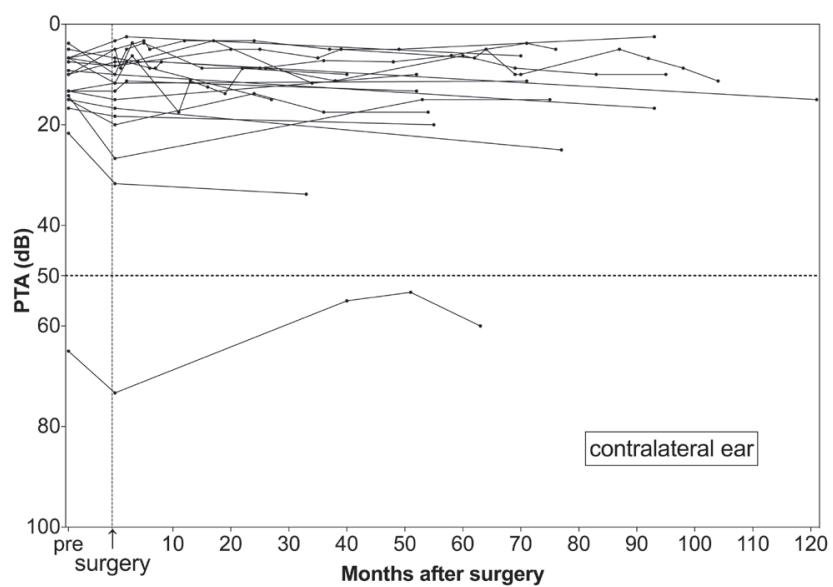

Fig. 1 Sequential plotting of pure tone average (PTA) changes in vestibular schwannoma patients treated with retrosigmoid removal. A: Operated ear. B: Contralateral ear. A vertical dotted line indicates the timing for a surgery. A horizontal dotted line shows PTA $=50 \mathrm{~dB}$.

A

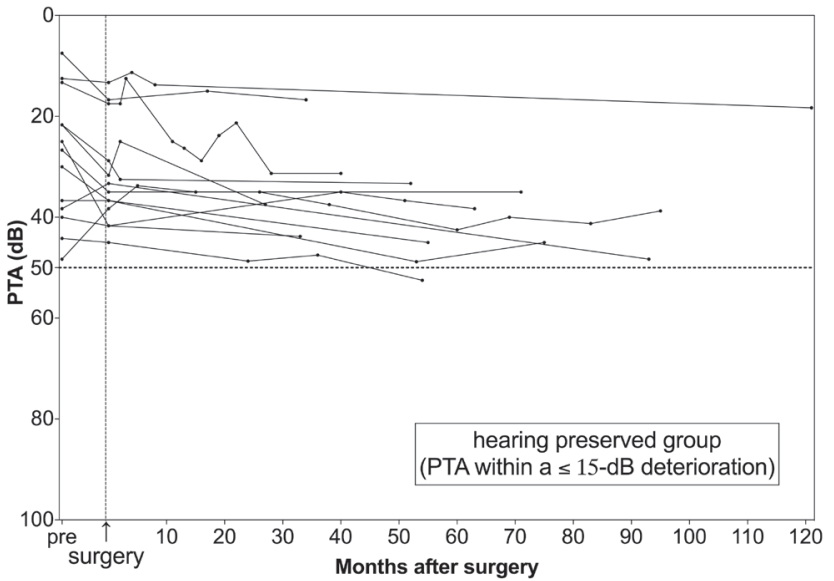

B

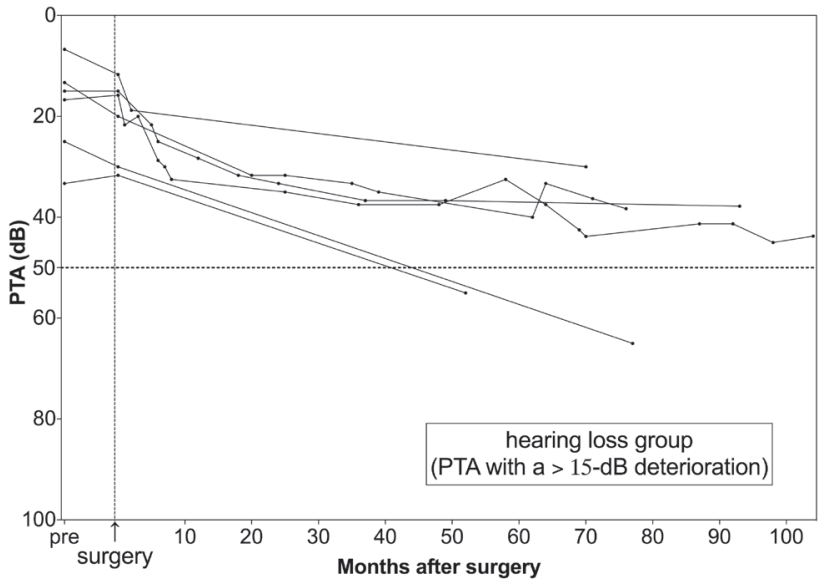

Fig. 2 Sequential plotting of pure tone average (PTA) changes of the operated ear in vestibular schwannoma patients treated with retrosigmoid removal. A: Patients with unchanged or remained PTA within a $\leq 15$-dB deterioration. B: Patients with PTA deteriorated $>15 \mathrm{~dB}$. A vertical dotted line indicates the timing for a surgery. A horizontal dotted line shows PTA $=50 \mathrm{~dB}$.

or $47.2 \%$, respectively (Fig. 3B).

Patient age was not a predictor for the long-term preservation of hearing in multivariate analysis; however, patients older than 65 years were not included in this analysis. Other factors including sex, tumor volume, preoperative hearing status, the waveform of preoperative ABR, tumor characteristics, extent of tumor removal, intraoperative appearance of the eighth cranial nerve, opening of the IAC, and immediate postoperative hearing status also did not correlate with the long-term preservation of hearing in multivariate analysis.

\section{Discussion}

We showed that the long-term preservation of serviceable hearing was achieved in $83 \%$ of patients with immediate postoperative serviceable hearing after removal of VS via retrosigmoid approach at a mean follow-up of 5 years. Six of 19 patients experienced 


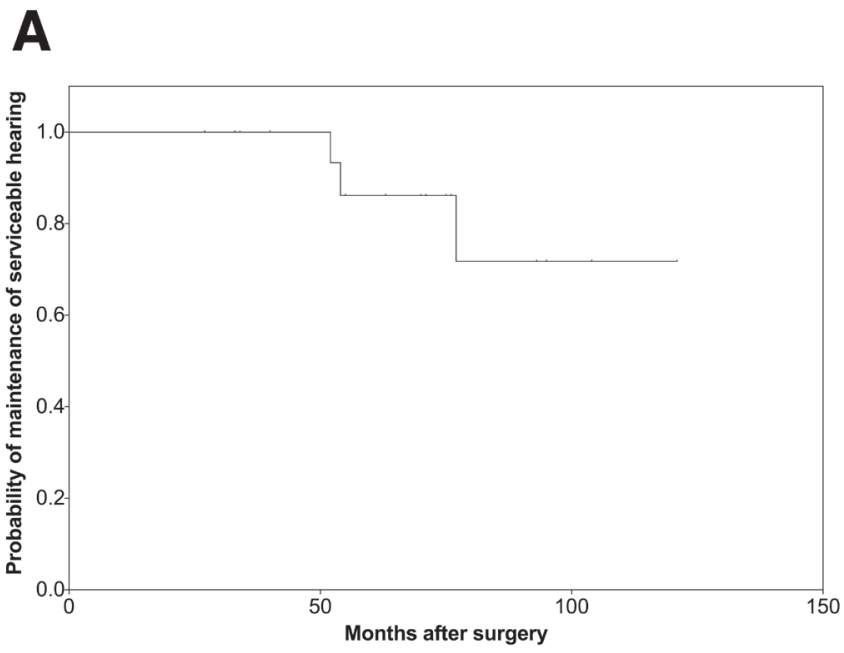

\section{B}

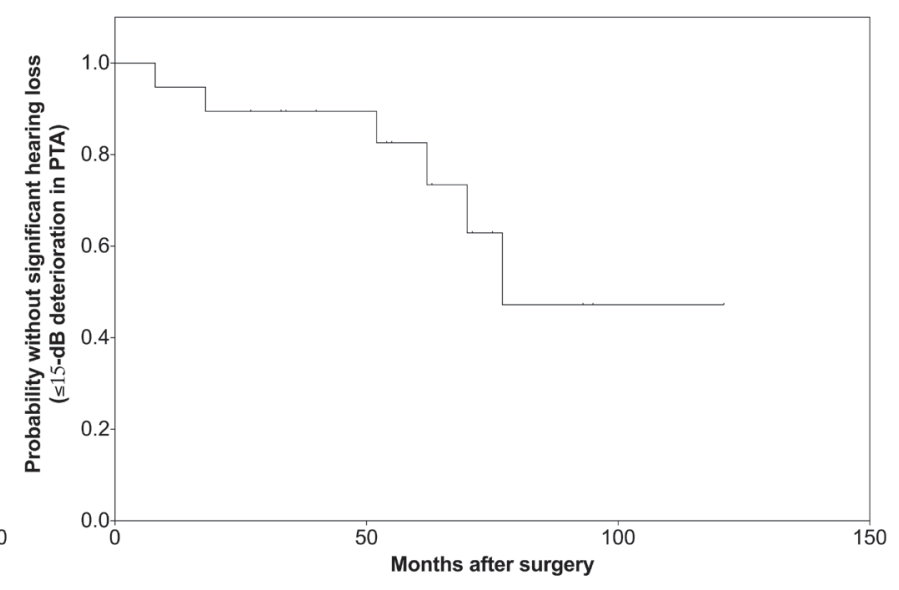

Fig. 3 Kaplan-Meier survival plot of hearing preservation in vestibular schwannoma patients treated with retrosigmoid removal. A: Probability of maintenance of serviceable hearing. B: Probability without significant hearing loss, i.e., deterioration of pure tone average (PTA) within $15 \mathrm{~dB}$.

transient hearing decline of the contralateral ear immediately after surgery; however, little is known about the postoperative changes in the hearing of the contralateral ear. Intraoperative loss of cerebrospinal fluid and brain shift could play a role in this condition. The information on the possibility of a postoperative transient decline in hearing function of the contralateral ear should be provided to all patients preoperatively.

The reported rates of hearing decline after VS surgery varied in range from $0 \%$ to $56 \%$. $^{2,3,7,11,13,14,16,21,23,27,31,32)}$ This variability is thought to be mainly due to the difference in the definition of hearing preservation, in the length of the follow-up, or in the surgical approaches. It is difficult to analyze the reported results of hearing preservation because there is no agreement as to what constituted "hearing." Some authors considered deterioration of any hearing a decline, ${ }^{2,3,11,14,21,23)}$ whereas others used specific audiometric parameters such as GR class ${ }^{7,13)}$ or the criteria of Thornton and Raffin ${ }^{16,27,31,32)}$ to define a decline of hearing. Several authors reported that the incidence of a decline in hearing quality tended to become higher the longer the postoperative follow-up.,13,16,27) A long and consecutive follow-up is required to elucidate the "long-term" hearing outcomes because sequential PTA plotting and Kaplan-Meier plotting in our and other's study clearly demonstrated that PTA deteriorated gradually over time ${ }^{13)}$; however, our results also demonstrated that deterioration of PTA in the early postoperative period may help to predict the long-term declines of hearing. In terms of surgical approach, there seemed to be no difference in the rate of hearing decline between middle fossa approach and retrosigmoid approach. The hearing decline rate has been reported to be $0-43 \%$ in patients treated via the retrosigmoid appr oach, ${ }^{2,11,14,16,21,23,31,32)}$ whereas $25-56 \%$ in patients treated via the middle fossa approach..$^{3,7,13)}$

The mechanisms of a long-term decline of hearing and its prognostic factors remain unclear. As possible mechanisms, microscopic tumor recurrence, ${ }^{19,33,34)}$ histopathological changes in the cochlea, ${ }^{27,32)}$ endolymphatic hydrops, ${ }^{5)}$ and the usage of muscle for packing the IAC were proposed. ${ }^{27)}$ Shelton et al. ${ }^{27)}$ reported that histopathological changes in the cochlea could be reduced by an usage of abdominal fat instead of temporal muscle. Inoue et al. ${ }^{13)}$ demonstrated that there was no difference in the course of hearing deterioration between the usage of abdominal fat ( $\mathrm{n}=12)$ and temporal muscle $(\mathrm{n}=8)$. Fat could cause a hearing decline; however, we avoided the direct contact of fat with the eighth cranial nerve in all cases. Several authors have demonstrated no correlation between a long-term hearing outcome and tumor volume, preoperative hearing quality, patient age, or symptoms. ${ }^{3,16,31)}$ In our study, we analyzed another factors including patient sex, the waveform of preoperative ABR, tumor constituency, extent of tumor removal, intraoperative appearance of the eighth cranial nerve, opening of the IAC, and immediate postoperative hearing status; however, we could not find the predictive factor for the long-term outcomes of serviceable hearing perhaps because of the limited number of our cases. More cases will be needed to clarify the factors related 
to the hearing outcome.

Long-term outcomes of hearing after conservative treatment in patients with VS have been reported to be poor. Godefroy et al. ${ }^{10)}$ reported that hearing was preserved after conservative treatment in $57 \%$ of patients whose hearing was useful at diagnosis during a mean follow-up of 2 years. Stangerup et al. ${ }^{28)}$ reported that only $41 \%$ of patients preserved good hearing after a mean follow-up of 4.7 years, and only $38 \%$ of the patients with only a small speech discrimination loss at diagnosis maintained good hearing during "wait and scan" management. Radiosurgery is a viable treatment modality for patients with VS and has the potential for hearing preservation $^{12,29)}$; however, Murphy et al. ${ }^{17)}$ and Arthurs et al. ${ }^{1)}$ asserted the importance of longterm follow-up because hearing can continue to decline over time in the majority of patients after radiosurgery. Chopra et al.4) reported that hearing preservation rate at 3 years after radiosurgery was $74 \%$; however, it declined to $44.5 \%$ at 10 years. Similarly, Prasad et al. ${ }^{22)}$ reported that no hearing deterioration was observed during the first 2 years of follow-up; however, hearing had subsequently declined and $62.5 \%$ of patients experienced worsening of hearing function at 8 years of follow-up. Paek et al. ${ }^{20)}$ demonstrated that the 5-year serviceable hearing preservation rate of patients with serviceable hearing after gamma knife radiosurgery was $46 \%$, and the 5-year hearing preservation rate (the rate remained at the same pre-gamma knife radiosurgery GR class) was $10 \%$. Even though a limited number of our cases, retrosigmoid removal appeared not to be inferior to radiosurgery in hearing preservation.

Our study demonstrated the long-term outcomes of serviceable hearing in the patients with unilateral VS treated via the retrosigmoid removal. Further study will be needed to clarify the mechanism underlying the long-term decline of serviceable hearing; however, our results demonstrate that the deterioration of PTA in the early postoperative period may help to predict the long-term outcomes of hearing. Hearing of the patients whose PTA does not decline within 6 months after surgery will be expected to be maintained over an extended time period. Since some patients can experience transient hearing decline of the contralateral ear immediately after surgery, this information should be provided to all patients preoperatively.

\section{Acknowledgments}

All the authors contributed to the work described in the article and all take responsibility for it.

\section{Conflicts of Interest Disclosure}

The authors have no conflict of interest and financial support in relation to this manuscript.

\section{References}

1) Arthurs BJ, Fairbanks RK, Demakas JJ, Lamoreaux WT, Giddings NA, Mackay AR, Cooke BS, Elaimy AL, Lee CM: A review of treatment modalities for vestibular schwannoma. Neurosurg Rev 34: 265-277; discussion 277-279, 2011

2) Atlas MD, Harvey C, Fagan PA: Hearing preservation in acoustic neuroma surgery: a continuing study. Laryngoscope 102: 779-783, 1992

3) Betchen SA, Walsh J, Post KD: Long-term hearing preservation after surgery for vestibular schwannoma. J Neurosurg 102: 6-9, 2005

4) Chopra R, Kondziolka D, Niranjan A, Lunsford LD, Flickinger JC: Long-term follow-up of acoustic schwannoma radiosurgery with marginal tumor doses of 12 to 13 Gy. Int J Radiat Oncol Biol Phys 68: 845-851, 2007

5) Clemis JD, Mastricola PG, Schuler-Vogler M: The contralateral ear in acoustic tumors and hearing conservation. Laryngoscope 91: 1792-1800, 1981

6) Ebersold MJ, Harner SG, Beatty CW, Harper CM, Quast LM: Current results of the retrosigmoid approach to acoustic neurinoma. J Neurosurg 76: 901-909, 1992

7) Friedman RA, Kesser B, Brackmann DE, Fisher LM, Slattery WH, Hitselberger WE: Long-term hearing preservation after middle fossa removal of vestibular schwannoma. Otolaryngol Head Neck Surg 129: 660-665, 2003

8) Gardner G, Robertson JH: Hearing preservation in unilateral acoustic neuroma surgery. Ann Otol Rhinol Laryngol 97: 55-66, 1988

9) Glasscock ME, Hays JW, Minor LB, Haynes DS, Carrasco VN: Preservation of hearing in surgery for acoustic neuromas. J Neurosurg 78: 864-870, 1993

10) Godefroy WP, Kaptein AA, Vogel JJ, van der Mey AG: Conservative treatment of vestibular schwannoma: a follow-up study on clinical and quality-of-life outcome. Otol Neurotol 30: 968-974, 2009

11) Goel A, Sekhar LN, Langheinrich W, Kamerer D, Hirsch B: Late course of preserved hearing and tinnitus after acoustic neurilemoma surgery. $J$ Neurosurg 77: 685-689, 1992

12) Hasegawa $T$, Fujitani $S$, Katsumata $S$, Kida $Y$, Yoshimoto M, Koike J: Stereotactic radiosurgery for vestibular schwannomas: analysis of 317 patients followed more than 5 years. Neurosurgery 57: 257-265; discussion 257-265, 2005

13) Inoue Y, Kanzaki J, Ogawa K, Hoya N, Takei S, Shiobara R: The long-term outcome of hearing preservation following vestibular schwannoma surgery. Auris Nasus Larynx 27: 9-13, 2000 
14) Jannetta PJ, Møller AR, Møller MB: Technique of hearing preservation in small acoustic neuromas. Ann Surg 200: 513-523, 1984

15) Koos WT, Day JD, Matula C, Levy DI: Neurotopographic considerations in the microsurgical treatment of small acoustic neurinomas. J Neurosurg 88: 506-512, 1998

16) McKenna MJ, Halpin C, Ojemann RG, Nadol JB, Montgomery WW, Levine RA, Carlisle E, Martuza R: Long-term hearing results in patients after surgical removal of acoustic tumors with hearing preservation. Am J Otol 13: 134-136, 1992

17) Murphy ES, Suh JH: Radiotherapy for vestibular schwannomas: a critical review. Int J Radiat Oncol Biol Phys 79: 985-997, 2011

18) Nakamizo A, Yoshimoto K, Amano T, Mizoguchi M, Sasaki T: Crocodile tears syndrome after vestibular schwannoma surgery. J Neurosurg 116: 1121-1125, 2012

19) Neely JG: Is it possible to totally resect an acoustic tumor and conserve hearing? Otolaryngol Head Neck Surg 92: 162-167, 1984

20) Paek SH, Chung HT, Jeong SS, Park CK, Kim CY, Kim JE, Kim DG, Jung HW: Hearing preservation after gamma knife stereotactic radiosurgery of vestibular schwannoma. Cancer 104: 580-590, 2005

21) Palva T, Troupp H, Jauhiainen T: Hearing preservation in acoustic neurinoma surgery. Acta Otolaryngol 99: 1-7, 1985

22) Prasad D, Steiner M, Steiner L: Gamma surgery for vestibular schwannoma. J Neurosurg 92: 745-759, 2000

23) Rosenberg RA, Cohen NL, Ransohoff J: Long-term hearing preservation after acoustic neuroma surgery. Otolaryngol Head Neck Surg 97: 270-274, 1987

24) Samii M, Carvalho GA, Nikkhah G, Penkert G: Surgical reconstruction of the musculocutaneous nerve in traumatic brachial plexus injuries. J Neurosurg 87: 881-886, 1997

25) Samii M, Gerganov V, Samii A: Improved preservation of hearing and facial nerve function in vestibular schwannoma surgery via the retrosigmoid approach in a series of 200 patients. J Neurosurg 105: 527-535, 2006
26) Sasaki T, Shono T, Hashiguchi K, Yoshida F, Suzuki SO: Histological considerations of the cleavage plane for preservation of facial and cochlear nerve functions in vestibular schwannoma surgery. J Neurosurg 110: 648-655, 2009

27) Shelton C, Hitselberger WE, House WF, Brackmann DE: Hearing preservation after acoustic tumor removal: long-term results. Laryngoscope 100: 115-119, 1990

28) Stangerup SE, Thomsen J, Tos M, Cayé-Thomasen P: Long-term hearing preservation in vestibular schwannoma. Otol Neurotol 31: 271-275, 2010

29) Tamura M, Carron R, Yomo S, Arkha Y, Muraciolle $\mathrm{X}$, Porcheron D, Thomassin JM, Roche PH, Régis J: Hearing preservation after gamma knife radiosurgery for vestibular schwannomas presenting with highlevel hearing. Neurosurgery 64: 289-296; discussion 296, 2009

30) Thornton AR, Raffin MJ: Speech-discrimination scores modeled as a binomial variable. J Speech Hear Res 21: 507-518, 1978

31) Tucci DL, Telian SA, Kileny PR, Hoff JT, Kemink JL: Stability of hearing preservation following acoustic neuroma surgery. Am J Otol 15: 183-188, 1994

32) Umezu H, Aiba T, Tsuchida S, Seki Y: Early and late postoperative hearing preservation in patients with acoustic neuromas. Neurosurgery 39: 267-271; discussion 271-272, 1996

33) Ylikoski J, Collan Y, Palva T, Jauhiainen T: Cochlear nerve in neurilemomas. Audiology and histopathology. Arch Otolaryngol 104: 679-684, 1978

34) Ylikoski J, Palva T, Collan Y: Eighth nerve in acoustic neuromas. Special reference to superior vestibular nerve function and histopathology. Arch Otolaryngol 104: 532-537, 1978

Address reprint requests to: Akira Nakamizo, $\mathrm{MD}, \mathrm{PhD}$, Department of Neurosurgery, Graduate School of Medical Sciences, Kyushu University, 3-1-1 Maidashi, Higashi-ku, Fukuoka, Fukuoka 812-8582, Japan. e-mail: nakamizo@ns.med.kyushu-u.ac.jp 